\title{
The Phenomenon of Enterprise Systems in Higher Education:Insights From Users
}

\author{
Ahed Abugabah \\ College of Business Administration \\ American University \\ Dubai, United Arab Emirates
}

\author{
Louis Sansogni \\ School of Business \\ Griffith University Brisbane, \\ Australia
}

\author{
Osama Abdulaziz Alfarraj \\ Computer Science Department \\ Community College, King Saud \\ University Riyadh, \\ Saudi Arabia
}

\begin{abstract}
Higher education has been strongly influenced by global trends to adopt new technologies. There has been a call by governments for universities worldwide to improve their performance and efficiency. In response, higher education institutions have turned to Enterprise Resource Planning systems (ERP) in order to cope with the changing environment and overcome the limitations of legacy systems as a means for integration and performance improvement advantages. However, failure rate of ERP implementation is high and debate still exists regarding the various contributions of the ERP systems to performance, especially at the user level, where the core values of information systems are represented and the actual benefits and impacts are created.
\end{abstract}

As consequence, this study evaluates the impacts of ERP systems on user performance in higher education institutions with a view to better understand ERP phenomenon in these institutions and determine whether or not these systems work well in such a complex environment. The study also developed and validated statistically a new model suggesting a more inclusive sight for examining ERPs utilization and impacts and combining the key ideas of three well-known and widely used information systems models.

Keywords-ERP systems; user performance; system quality; higher education

\section{INTRODUCTION}

In order to deal with today's changing environment and overcome the limitations of legacy systems, organizations have turned to Enterprise Resource Planning (ERP) systems [1;2]. ERP systems have been adopted by numerous organizations and support most industries including airlines, telecommunications and education. These systems fundamentally represent the most significant development in terms of costs and corporate use of information systems $[1 ; 3]$.

ERP systems permit the seamless flow of information across the entire organization and address the problem of fragmentations of information or "Islands of information" in organizations [1]. Since the emergence of ERP packages in the late 1990s, they have become popular among practitioners and IS researchers alike [2]. According to Gartner Inc., the revenue for ERP software around the world in 2011 is US \$253.7 billion; this amount represents an increase of $7.5 \%$ compared to 2010 's, as stated in [3].
Although ERP systems are being used widely around the world with billions of dollars and countless hours spent in implementing such systems, they bring along many problems and weaknesses. Most of these implementations are unsuccessful and fail through "inadequate adoption", this being just one of a number of failure factors [4]. As such, debate still exists regarding the various contributions of the ERP systems to performance, as the failure rate of implementation is high. In particular, failure to respond to the users' needs leads many large information systems' projects, including ERP ones, to fail making it impossible to realize the expected benefits in today's rapidly evolving business environment $[5 ; 6]$.

Consequently, especially in the last decade, ERP systems have begun to attract the attention of researchers. Little attention however, has been given to their adoption in higher education. Organizations, including higher education, aim at obtaining value from ERP systems through improved overall efficiency, operational efficiency and business efficacy [7; 8].However, this possibility remains unclear in higher education, foreshadowing the need for investigations to see whether or not ERP systems deliver sustainable outcomes and whether or not they help to improve performance and enhance productivity.

\section{ERP SySTEMS IN HIGHER EDUCATION}

Higher education institutions have been strongly influenced by global trends to adopt new technologies. There has been a call by governments for universities worldwide to improve their performance and efficiency [4]. Challenges including increasing expectations of stakeholders such as students and governments, decreasing governmental support, meeting quality and performance requirements, and maintaining competitive education environments have pressured universities to adopt new strategies in order to improve their performance [5]. In response to the many challenges faced, higher education institutions have turned to ERP systems in order to cope with the changing environment [6] and to replace aging management and administration computer based systems [7]. This consequently would improve learning services by providing better managerial tools [8] thereby increasing their pace of organizational change and effectiveness $[5 ; 9]$.

ERP systems in universities can provide academic entities including schools and departments with completely functional applications for research and teaching [10]. 
They improve information access for planning and managing the institution, and enable users to access students' information, academic records and other data needed to complete their daily work [11], leading thus to improved business processes and services provided to the faculty, students and employees [8; 12].

Even though, implementation of ERP systems in higher education institutions is often described as extremely difficult. Expenses and risks involved are high. It is also sometimes unsuccessful or ineffective, whereas the return on investments is medium to long-term. Research on ERP systems in higher education reported a large number of failures and/or inadequate adoption of ERPs [13]. For example, EDUCAUSE conducted series of studies to assess ERP systems for tertiary institutions $[8 ; 14]$ reporting King that $50 \%$ of these implementations were over budget and over timeline schedules. Recent research claimed that as many as $60 \%$ to $80 \%$ percent of all ERP systems fail due to lack of meeting expected outcomes [15] and/or lack of performance improvement, with users expressing dissatisfaction with their performance.

Although ERP systems are the largest information systems' project adopted by universities, with significant resources allocated to implementation(e.g. higher education institutions spent more than five billion dollars in the last few years on ERP investments) [11], little research has been conducted on ERP implementations in universities compared to other environments [9]. At best, these studies brought about the identification of a number of critical factors related to the ERP implementation in higher education such as, staff training [10; 4], leadership and culture [15], change management, system functionality [16], ERP integration with education processes $[14 ; 17 ; 18 ; 19 ; 20]$, the evolution of ERP systems and the university curriculum [21; 11], and the ability of ERP systems to support business processes in universities [22].

Overall, prior research on ERPs revealed some important results, opening the path for new empirical investigations on ERP systems in a university environment, especially using ERP systems in the classroom for learning and teaching purposes [23] such as the usefulness of using ERP systems for enhancing learning by providing ways to transform the classroom into a real business environment [24].

With the spotlight of prior research mainly focused on success and failure factors and the successfulness of the ERP implementation other important issues at the user level such as user evaluation and user performance of ERPs thus remain elusive [25]. As consequence, this study focuses on ERPs' users to evaluate the impacts of ERP systems on user performance in higher education institutions with a view to better understand ERP phenomenon in these institutions. The study was designed to answer several questions related to how ERP systems affect user's performance, whether ERP systems improve performance, and identify the most significant factors that affect user performance within the context of ERP systems in higher education.

\section{RESEARCH APPROACH AND METHODOLOGY}

A survey methodology was used to gather data from ERP users in universities. The questionnaire was synthesized after an extensive review of the IS and ERP literature. The study was carried out in 6 large universities in Australia implemented several modules of ERP systems in different functional units such as human resource, students administration and finance. The respondents numbered 387 ERP users in total from various functional areas in these universities. The name of the university is withheld due to our non-disclosure agreement with the executives.

Measurement items used in the operationalization of the instrument were adopted from relevant prior research as listed in Appendix 2 [26; 27; 28]. The factors investigated in this study consolidated the main factors investigated in three well known IS models as illustrated in the study model below

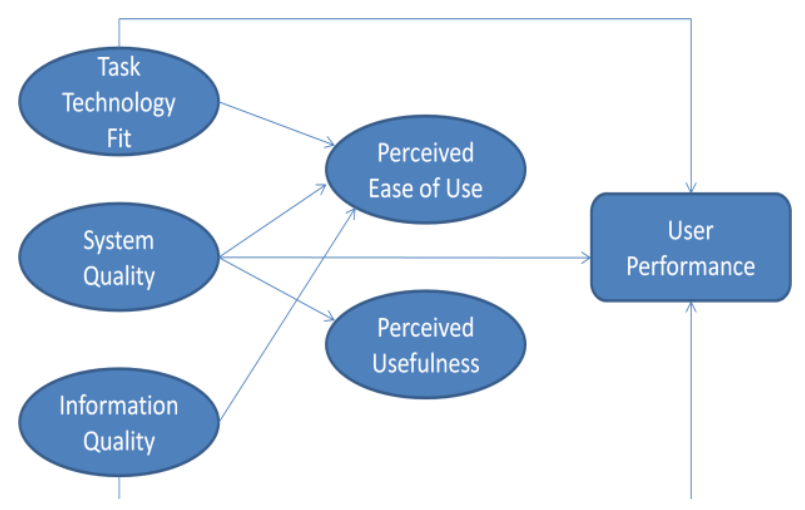

Fig. 1. The study model

\section{A. Validity and Reliability}

The reliability and validity of the measurement instrument was carried out using reliability and factor analysis. The entire instrument, as well as the individual variables, achieved high levels of reliability. The results showed that the reliabilities of the constructs (Cronbach's coefficient $\alpha$ ) ranged from 0.84 for PU to 0.97 for UP, indicating high reliability, as mentioned in Table I (Appendix 1).

Instrument validity: Factor analysis was carried out to examine measurement construct validity. Typically construct validity is considered to be satisfactory when items load high on their respective constructs (factors). The cut-off point used in this analysis was .5 , as recommended by [30; 31]. All correlations below this point were considered low. As shown in Table I (Appendix 1), all items had high loadings on their respective factors, with most of items above 0.70 , demonstrating high construct validity.

\section{DISCUSSION AND FINDINGS}

Multiple regression analysis (MRA) was used to assess the effects of various factors included in this study on user performance. MRA is useful to identify significant contributions made by these factors to predicting user performance, rather than correlations, by themselves, as they do not explain all the relationships between factors in a study.

This is considered to be appropriate given that most prior studies similar to this study have used regression analyses to assess the relationships between the factors and thus doing the 
same here will facilitate comparison of the study results with previous ones $[32 ; 33 ; 28]$.

To evaluate the overall impact of ERP systems on user performance, a multiple regression analysis was performed in two stages. The first stage utilized TTF, SQ, IQ, PEOU and PU as independent factors, while the second stage used only the PEOU and PU factors. It should be remembered, however, that user performance (UP) was self-assessed, so the UP measure reflects self-user performance.

The results of the analyses are presented in Table II(Appendix 1) and indicated that the whole model has a significant positive relationship with user performance. As shown in Table II(Appendix 1) ( $\mathrm{F}=20)$, which is significant at the $(\mathrm{P}<.01)$ level. This relationship is strong $(\mathrm{R}=.782)$, explaining $61.2 \%$ of the variance in user performance and thus hypothesis $\mathrm{H} 1$ is supported, which is consistent with the results of previous ERP systems' research (such as [34]).

Regression weights, especially $\beta$ values, can be used to compare the individual contributions of independent factors [35]. The results showed that IQ did not contribute significantly and uniquely to explaining user performance beyond the explanation provided by the other independent factors, while TTF contributed significantly to user performance. The largest unique and significant contribution for predicting user performance was provided by SQ $(\beta=$ .604). An overall multiple regression was also conducted, using all factors, including PU and PEOU, to check the contribution of each factor in explaining user performance in the presence of PU and PEOU. In other words, the second test was to explain how PU and PEOU mediated the systems' impact on user performance, as shown in Table II (Appendix 1).

A regression analysis was also employed to identify the factors that contribute significantly to predicting user performance. The importance of each factor was also displayed in Table II (Appendix 1). The significant contribution for each factor is shown in column labelled B. PU was the strongest protector $(\beta=.425)$, explaining $71.7 \%$ of the variance in user performance, while the second factor was SQ $(\beta=.407)$, explaining $58.5 \%$ of the variance in user performance. Thus, PEOU plays a critical role in increasing the impact of ERP systems on user performance.

The findings demonstrated that ERP systems impact user performance in higher education significantly and positively. The results of the analysis showed that all above mentioned factors contribute to user performance and explain a high percentage of the variance in user performance. However, this result was further explored to identify the contribution for each factor on the variance in user performance.

Previous studies, which investigated ERP impacts on users indicated that SQ and IQ are very important factors that affect benefits of use [36]. They however mentioned that SQ plays more important roles than its IQ counterpart in terms of influencing ERP benefits. In this sense, [37] found that SQ and IQ are considered the most important factors when evaluating ERP systems' impacts. Others mentioned that SQ and system integration are two important factors that contribute towards the formation of the overall systems' impacts. This study demonstrated the importance of all of the abovementioned factors and explored the relative contribution of each to user performance.

ERP users reported that their performance is improved through experience thereby improving efficiency and effectiveness. The results showed that users believe that ERP systems provide high quality information, which helps reduce errors and solve performance problems when they occur. Furthermore, SQ and TTF play an important role in enhancing performance quality and increasing the quantity of work performed by users. The results showed a satisfactory level of fit between ERP systems and users' needs, and tasks requirements, considering the sophisticated characteristics of ERP systems. It was found that users believe that ERP systems have the required compatibility and learn ability that helps them in performing their tasks.

Considering the unique characteristics of ERP systems, the current study contributes greatly in the identification of the determinants of user performance in practice. That is, the design of ERP systems should fit exactly the tasks that users are engaged with. The findings of the study suggest that TTF can affect PEOU and PU directly. For example, the more flexible and convenient ERP systems are, the more they will be perceived as useful PU and easy to use PEOU.

In other words, ERP users believe that ERP systems are helpful in supporting the performance of their tasks and also easy to use if they are designed to be applicative and fit to their tasks. Careful consideration of users' needs and task requirements in a specific industry will help guide system designers and practitioners with the design and implementation of ERP systems, in light of the diversity of vendors, designers, ERP systems functionalities, and industries [38].

\section{CONCLUSION}

This study investigated the impact of enterprise resource planning systems on user performance in higher education. The findings of this study, for the most part, are consistent with previous studies on ERP systems such as $[34 ; 32 ; 28]$, and several others that have extended TAM and TTF models, though there are also some differences between our results and the others such as [32]. The results of the study demonstrated that PU has a positive direct and indirect impact on system use and user performance. In fact, among all factors investigated, PU has a large effect on and/or mediated the impacts of other factors on performance. This result is significant as it shows that in a complex IS environment, just as in non-complex environments, PU of a system is perhaps more important than its ease of use [32]. Thus, designing attempts focused on enhancing PU of the ERP systems will be worthwhile since it is more likely to lead to more system impacts and an improved performance. Unlike previous studies that used PU measures to investigate the system impacts in most cases and/or user satisfaction to measure system success and system usage [40; 41], the current study provides significant progress in measuring systems' impacts and user performance.

The implications of the results revealed that meaning beyond the information obtained from the ERPs, the fitness and consistency between ERP applications and work aspects, 
the exact meaning of information obtained from the ERP, and the correct meaning of the information on the ERP systems were all important factors in predicting user performance. Participants of the study indicated that these factors were adequate to handle the work processing needs and led consequently to improved performance. For example, adequacy of the ERP system has a significant effect on user performance. Therefore, the design of an ERP system's interface and functionality must be aligned with user needs and task requirements and also should be easy to navigate among different ERP modules.

This study provides more clarifications and explanations about the potential benefits and outputs of ERP systems for users. This is becoming important as organizations, especially with the increasingly huge investments on ERP systems' installations made by higher education institutions. The little empirical research in this environment available especially at user level, associated with lack of empirical research in this environment made the benefits of the systems unrecognized yet [42; 43]. The study is deemed to be useful in explaining how users can obtain values from ERP systems and reflect them in their task and job accomplishments.

\section{REFERENCES}

[1] Eric, W., Ngai, Chuck, C., \& Law, H. (2007). An investigation of the relationships between organizational factors, business process improvement, and ERP success An International Journal, 14(3), 287406.

[2] Davenport, T. (1998). Putting The Enterprise into The Enterprise Systems. Harvard Business Review, 76(4), 121-132.

[3] Ifinedo, P. (2011). Examining the influences of external expertise and in-house computer/IT knowledge on ERP system success. The Journal of Systems and Software 84, 2065-2078.

[4] Allen, D., \& Kern, T. (2001). Enterprise Resource Planning Implementation: Stories of Power, Politics, and Resistance at the Proceedings of the IFIP TC8/WG8.2 Working Conference on Realigning Research and Practice in Information Systems Development: The Social and Organizational Perspective Idaho.USA.

[5] Fisher, M. D. (2006). Staff Perceptions of an Enterprise Resource Planning System Implementation: A Case Study of three Australian Universities. Unpublished PhD Thesis, Central Queensland University, Queensland.

[6] McCredie, J., \&Updegrove, D. (1999). Enterprise System Implementations: Lessons from the Trenches. CAUSE/EFFECT, 22(4), $1-10$.

[7] Pollock, N., \&Cornford, J. (2001). Customising Industry Standard Computer Systems for Universities: ERP Systems and the University as an 'Unique'OrganizationEngland: UMIST.

[8] Kvavik, R., Katz, R., Beecher, K., CARUSO, J., \& KING, P. (2002). The Promise and Performance of Enterprise Systems for Higher Education. EDUCAUSE, 4, 5-123.

[9] Nielsen, J. (2002). Critical success factors for implementing an ERP system in a university environment: A case study from the Australian HES. Griffith University, Brisbane.

[10] Watson, E., \& Schneider, H. (1999). Using ERP in education Communications of AIS, 1(9), 12-24.

[11] Davis, M., \&Huang, Z. (2007). ERP in Higher Education: A Case Study of SAP and Campus Management. Issues in Information Systems, VIII (1), 120-126.

[12] King, P., Kvavik, R., \& John, V. (2002). Enterprise Resource Planning Systems in Higher Education. EDUCAUSE, 22, 1-5.

[13] Botta-Genoulaz, V., \& Millet, P. (2006). An investigation into the use of ERP systems in the service sector. International Journal of Production Economics, 99(1), 202-221.
[14] Judith, P. (2005). Good Enough! IT Investment and Business Process Performance in Higher Education ECAR, key findings, 2005

[15] Mehlinger, L. (2006). Indicators of Successful Enterprise Technology Implementations in Higher Education Unpublished Doctorate Thesis Morgan state University, Morgan state.

[16] Vevaina, P. (2007). Factors affecting the implementation of enterprise systems within government organizations in New Zealand. Auckland University of Technology, Auckland

[17] Cynthia, L., \& Harold, W. W. (Writer) (2004). Appropriating Enterprise Resource Planning Systems in Colleges of Business: Extending Adaptive Structuration Theory for Testability.

[18] Todd, J., Alden, C. L., James, M., \& Jon, O. (Writer) (2004). A Customized ERP/SAP Model for Business Curriculum Integration.

[19] Casper, D., \& Dirk-Jan, S. (Writer) (2004). Best Practices of Business Simulation with SAP R/3.

[20] Jarmoszko, A. T., \& Michael, G. (2004). Choosing an ERP-type System for a Belarus Enterprise. Journal of Information Systems Education, 15(3), 255.

[21] Paul, H., Brendan, M., \& Andrew, S. (Writer) (2004). Second Wave ERP Education.

[22] Jane, F., Ulric, J. G., Jr., Catherine, U., \& George, H. (Writer) (2004). Twelve Tips for Successfully Integrating Enterprise Systems across the Curriculum.

[23] Yvonne Lederer, A., Gail, C., Glenn, S., \& Albert, L. H. (Writer) (2004). Enterprise Systems Education: Where Are We? Where Are We Going?

[24] Noguera, H. J., \& Watson, F. E. (Writer) (2004). Effectiveness of using an enterprise system to teach process-centered concepts in business education.

[25] Lope Ahmad, R., Othman, Z., \&Mukhtar, M. (2011). Campus ERP implementation framework for private institution of higher learning environment in Malaysia. WSEAS Transactions on advances in engineering education 1(8), 1-12.

[26] Goodhue, D., \& Thompson, R. (1995). Task-technology fit and individual performance. MIS Quarterly, 19(2), 213-233.

[27] Delone, W., \& McLean, E. (1992). Information systems success: the quest for the dependent variable. Information systems research 3(1), 6095.

[28] Calisir, F., \&Calisir, F. (2004). The relation of interface usability characteristics, perceived usefulness and perceived ease of use to end user satisfaction with enterprise resource planning systems. Computer in Human Behavior 20(505-515)

[29] Golafshani, N. (2003). Understanding Reliability and Validity in Qualitative Research The Qualitative Report, 8(4), 597-607

[30] Goodhue, D., Klein, B., \& March, S. (2000). User evaluations of IS as surrogates for objective performance. Information \& Management, 38, $87-101$.

[31] Hong, K., \& Kim, Y. (2002). The critical success factors for ERP implementation: an organizational fit perspective. Information \& Management, 40(25-40).

[32] Amoako-Gyampah, K. (2007). Perceived usefulness, user involvement and behavioral intention: an empirical study of ERP implementation. Computers in Human Behavior, 23(3), 1232-1248.

[33] Lucas, H., \&Spitler, V. (1999). Technology use and performance: A field study of broker workstations. Decision Sciences, 30(2), pp 291322.

[34] Kositanurit, B., Ngwenyama, O., \&Osei-Bryson, K. (2006). An exploration of factors that impact individual performance in an ERP environment: an analysis using multiple analytical techniques. European Journal of Information Systems, 15, 556-568.

[35] Pallant, J. (2007). SPSS Survival Manual: A step by step guide to data analysis using SPSS (3rd Ed.). New South Wales: Allen \&Unwin.

[36] Chien, S., \&Tsaur, S. (2007). Investigating the success of ERP systems: Case studies in three Taiwanese high-tech industries. Computers in Industry, 58(8), 783-793. 
[37] Ifinedo, P., \&Nahar, N. (2006). Quality Impact and Success of ERP Systems: A Study Involving Some Firms in the Nordic-Baltic Region. Journal of Information Technology Impact 6(1), 19-46.

[38] Yen, D. C., Wu, C.-S., Cheng, F.-F., \& Huang, Y.-W. (2010). Determinants of users' intention to adopt wireless technology: An empirical study by integrating TTF with TAM. Computers in Human Behavior, In Press, Corrected Proof.

[39] Wu, J.-H., Chen, Y.-C., \& Lin, H.-H. (2004). Developing a set of management needs for IS managers: a study of necessary managerial activities and skills. Information \& Management, 41(4), 413-429.

[40] Wu, J., \& Wang, W. (2006). Measuring KMS success: A respecification of the DeLone and McLean's model. Information \& Management, 43(6), 728-739.

[41] Kwahk, K.-Y., \&Ahn, H. (2009). Moderating effects of localization differences on ERP use: A socio-technical systems perspective. Computers in Human Behavior, In Press, Corrected Proof.

[42] Sun, Y., Bhattacherjee, A., \& Ma, Q. (2009). Extending technology usage to work settings: The role of perceived work compatibility in ERP implementation. Information \& Management, 46, 351-356.
[43] Hellens, L., Nielsen, S., \&Beekhuyzen, J. (2005). Qualitative case studies on implementation of enterprise wide systems. Hershey: Idea Group Publishing.

[44] Goodhue, D., \& Thompson, R. (1995). Task-technology fit and individual performance. MIS Quarterly, 19(2), 213-233.

[45] DeLone, W., \& McLean, E. (2003). The DeLone McLean model of information system success: a ten-year update. Journal of Management Information Systems, 19(4), 3-9.

[46] Davis, F. (1989). Perceived usefulness, perceived ease of use, and user acceptance of information technology. Management Information System Quarterly 13(Sep), 318-340.

[47] Davis, F., Bagozzi, P., \&Warshaw, R. (1989). User acceptance of computer technology: a comparison of two theoretical models. Management Science 35, 982-1003.

[48] Goodhue, D., Klein, B., \& March, S. (2000). User evaluations of IS as surrogates for objective performance. Information \& Management, 38, $87-101$

\section{APPENDIX 1}

TABLE I. RESULTS OF FACTOR ANALYSIS AND MEASUREMENT RELIABILITY $(\mathrm{N}=387)$ *

\begin{tabular}{|c|c|c|c|c|c|c|c|}
\hline Factors/Items & Loading & Mean & SD & Factors/Items & Loading & Mean & SD \\
\hline$\underline{\operatorname{TTF}}(\alpha=.90)$ & & 4.9 & .96 & Corr1 & .75 & 3.2 & .93 \\
\hline Loc1 & .74 & 5.3 & 1.39 & Corr2 & .60 & 3.3 & .92 \\
\hline Loc2 & .81 & 4.9 & 1.39 & $\underline{\mathrm{PU}}(\alpha=.84)$ & & 3.9 & .78 \\
\hline Com2 & .74 & 5.4 & 1.12 & PU1 & .69 & 3.9 & .83 \\
\hline Com3 & .75 & 5.3 & 1.14 & PU2 & .67 & 4.2 & 1.03 \\
\hline ITsub2 & .84 & 4.7 & 1.33 & PU3 & .76 & 3.7 & .92 \\
\hline ITsub3 & .85 & 4.8 & 1.31 & PU4 & .73 & 3.7 & .98 \\
\hline Ade1 & .84 & 4.8 & 1.34 & $\underline{\operatorname{PEOU}}(\alpha=.89)$ & & 3.3 & .89 \\
\hline Ade2 & .60 & 4.8 & 1.36 & PEOU1 & .72 & 3.2 & 1.00 \\
\hline Mea1 & .74 & 4.5 & 1.30 & PEOU2 & .85 & 3.2 & .97 \\
\hline Mea2 & .78 & 4.3 & 1.30 & PEOU3 & .89 & 3.4 & .98 \\
\hline IQ $(\alpha=.87)$ & & 3.6 & .61 & & & & \\
\hline Accees1 & .71 & 3.5 & .90 & $\underline{\mathrm{UP}}(\alpha=.97)$ & & 4.5 & 1.14 \\
\hline Access2 & .82 & 3.4 & .91 & Efficil & .81 & 4.6 & 1.28 \\
\hline Complet1 & .50 & 3.4 & .88 & Effici2 & .77 & 4.9 & 1.34 \\
\hline Complet2 & .50 & 3.7 & .76 & Effici3 & .76 & 4.7 & 1.29 \\
\hline Tim1 & .53 & 3.6 & .86 & Effici4 & .76 & 4.6 & 1.32 \\
\hline Tim2 & .69 & 3.6 & .87 & Effici5 & .65 & 4.6 & 1.24 \\
\hline SQ $(\alpha=.87)$ & & 3.3 & .63 & Effici6 & .78 & 4.7 & 1.32 \\
\hline Integ1 & .77 & 3.1 & .85 & Effici7 & .74 & 4.8 & 1.35 \\
\hline Integ2 & .78 & 3.3 & .83 & Effici8 & .69 & 4.7 & 1.34 \\
\hline Integ3 & .58 & 3.2 & .99 & Effec1 & .715 & 4.5 & 1.38 \\
\hline Relia1 & .66 & 3.7 & .87 & Effec2 & .61 & 4.4 & 1.32 \\
\hline Relia2 & .83 & 3.6 & .79 & Effec3 & .60 & 4.7 & 1.30 \\
\hline Restime1 & .73 & 3.3 & .96 & Crea1 & .91 & 3.9 & 1.52 \\
\hline Restime2 & .74 & 3.2 & .94 & Crea1 & .83 & 3.7 & 1.57 \\
\hline
\end{tabular}

*Only loadings of 0.5 or above are shown; ** Values in parenthesis represent Cronbach's alpha 
TABLE II. ERP IMPACTS ON PERCEIVED USER PERFORMANCE

\begin{tabular}{|c|c|c|c|c|c|c|c|c|c|c|}
\hline \multirow[b]{2}{*}{$\begin{array}{l}\text { Independent } \\
\text { Factors * }\end{array}$} & \multicolumn{5}{|c|}{ User performance } & \multicolumn{5}{|c|}{ User performance through $P E O U \& P U$} \\
\hline & B & S.E & $\beta$ & $\mathbf{t}$ & Sig & B & S.E & $\boldsymbol{\beta}$ & $\mathrm{t}$ & Sig \\
\hline TTF & .198 & .056 & .167 & 3.54 & .005 & .09 & .048 & .07 & 1.41 & .06 \\
\hline IQ & .146 & .093 & 077 & 1.56 & .110 & .14 & .080 & -.07 & -.25 & .07 \\
\hline SQ & 1.079 & .083 & 604 & 13.0 & .001 & .73 & .075 & 407 & 9.228 & .001 \\
\hline PU & & & & & & 62 & .052 & .425 & 11.315 & .001 \\
\hline PEOU & & & & & & .19 & .049 & 149 & 3.620 & .001 \\
\hline $\mathbf{R}$ & & .780 & & & & & .850 & & & \\
\hline $\mathbf{R}^{2}$ & & .610 & & & & & .730 & & & \\
\hline $\mathbf{F}$ & & 201 & & & & & 210 & & & \\
\hline
\end{tabular}

TABLE III. THE SIGNIFICANT CONTRIBUTION OF EACH FACTOR IN PREDICTING USER PERFORMANCE

\begin{tabular}{|c|c|c|c|c|c|}
\hline Factors* & $\boldsymbol{R}$ & $R^{2}$ & Adjusted $R^{2}$ & $\beta$ & S. $E$ \\
\hline SQ & .765 & .586 & .585 & .407 & .73578 \\
\hline $\mathbf{P U}$ & .847 & .718 & .717 & .425 & .60771 \\
\hline PEOU & .857 & .731 & .728 & .153 & .59500 \\
\hline
\end{tabular}

APPENDIX 2

\begin{tabular}{|c|c|c|}
\hline Constructs & Measurement items & Source \\
\hline Task technology fit $* *$ & & [44], [26] \\
\hline Locatability & $\begin{array}{l}\text { 1. It is easy to determine what application is available and where to do my job. } \\
\text { 2. It is ease to locate the data in the ERP applications that I use. }\end{array}$ & \\
\hline Compatibility & $\begin{array}{l}\text { 1. ERP applications that I use are consistent with my tasks. } \\
\text { 2. ERP applications fit with my work aspects. }\end{array}$ & \\
\hline Meaning & $\begin{array}{l}\text { 1. The exact meaning of information obtained from the ERP, relating to my task, is easy to find out. } \\
\text { 2. The correct meaning of the information is obvious and clear on the ERP software }\end{array}$ & \\
\hline Adequacy & $\begin{array}{l}\text { 1. The ERP software that the university has meets my task requirements. } \\
\text { 2. The ERP software is adequate to handle my work processing needs. }\end{array}$ & \\
\hline IT support & $\begin{array}{l}\text { 1. I get the kind of quality computer-related training that I need. } \\
\text { 2. The IT people I deal with understand my work objectives. } \\
\text { 2. It is easy to get IT support and advice from IT people when I use ERP applications. }\end{array}$ & \\
\hline Information quality * & & [27], [45] \\
\hline Accuracy & 1. Our ERP system provides me with accurate information. & \\
\hline Relevancy & 1. Our ERP system provides relevant information. & \\
\hline Timeliness & $\begin{array}{l}\text { 1. Our ERP system provides me with the information I need in a timely manner. } \\
\text { 2. The information in our ERP system is timely and regularly updated. } \\
\text { 3. Getting information from our ERP system on time improves my work quality. }\end{array}$ & \\
\hline Completeness & $\begin{array}{l}\text { 1. I can find complete information when I need it in our ERP system. } \\
\text { 2. The information in our ERP system is sufficient to do my work. }\end{array}$ & \\
\hline Accessibility & $\begin{array}{l}\text { 1. The information in our ERP system is easily accessible. } \\
\text { 2. Information in our ERP system is easy retrievable. } \\
\text { 3. Convenience of information in our ERP system saves my time in my job. }\end{array}$ & \\
\hline Perceived usefulness * & $\begin{array}{l}\text { 1. Our ERP system is useful for my job performance. } \\
\text { 2. I cannot accomplish my job without the ERP system. } \\
\text { 3. Our ERP system supports me in attaining my overall performance goals. } \\
\text { 4. Our ERP system makes it easier to do my job. }\end{array}$ & [46], [47] \\
\hline Perceived ease of use* & $\begin{array}{l}\text { 1. Our ERP system is user friendly. } \\
\text { 2. It is easy to learn how to use our ERP system. } \\
\text { 3. I find the ERP system is easy to use. }\end{array}$ & [46], [47] \\
\hline $\begin{array}{l}\text { System quality } * \\
\text { Reliability }\end{array}$ & $\begin{array}{l}\text { 1. Our ERP system is reliable. } \\
\text { 2. Our ERP system has consistent information. }\end{array}$ & [44], [48] \\
\hline
\end{tabular}


Correctness

Response time

Integration

\section{User performance**}

Efficiency

Effectiveness

Creativity
1. I find it easy to correct the errors related to my work by using our ERP system.

2. Our ERP system helps me reduce the errors in my job.

1. Our ERP system reacts and responds quickly when I enter the data.

2. Our ERP system responds quickly to my inquiries.

1. Our ERP system allows for integration with other systems.

2. Our ERP system effectively combines data from different areas of the university.

3. Our ERP system is designed for all levels of user.

1. I can accomplish my work quickly because of the ERP system quality.

2. Our ERP system lets me do more work than was previously possible.

3. Our ERP system has a positive impact on my productivity.

4. Our ERP system reduces the time taken to accomplish my tasks.

5. Our ERP system increases the cases I perform in my job.

6. Using our ERP system in my job enables me to accomplish tasks more quickly.

7. Overall, our ERP system improves my efficiency in my job.

8. Our ERP improves my performance quality.

1. Our ERP helps me solve my job problems.

2. Our ERP reduces performance errors in my job.

2. Our ERP system enhances my effectiveness in my job.

1. Our ERP helps me to create new ideas in my job.

2. Our ERP system enhances my creativity.

3. Overall our ERP system helps me achieve my job goals. 